\title{
Discussion on the Cultivation Pattern of Applied Costume Designers
}

\author{
Zhihui Wang \\ School of Design \\ Jilin University of the Arts \\ Changchun, China
}

\begin{abstract}
Nowadays, most of researches on costume designer cultivation patterns reform in high educational institutes are conducted in priority universities, yet there are few researches on applied costume designer cultivation patterns reform. In China, undergraduate educational institutes are in an absolute majority among professional colleges and universities, however, due to a series of causes such as short term establishment or irrational teaching structure and more, many problems arise out of the school running, whose functions should be but not completely exerted, and most of graduates majoring in costume design will need a long term transition period before being adapted to enterprise requirements after graduation, who are still far falling behind what costume enterprise want. Generally most graduates majoring in costume design are capable of freehand sketching, good at representing costume artistic effect, yet poor in hand operation and comprehensive skills, they have few knowledge about costume enterprises to take jobs in costume enterprises. This article tries to solve the problems through analysis, raising researches on applied costume design cultivation patterns reform, which is expected to promote and attract more researches on the basis of investigation and researches of the topic in order to improve the costume education, create a costume design educational pattern meeting the current social background, follow the social development demand so as to make a bit of contributions to the costume design education and costume enterprise development and to the fashionable industry in the country.
\end{abstract}

Keywords-applied; costume design; cultivation patter; educational pattern

\section{INTRODUCTION}

Through over three-decade exploration and development after China's opening up and reforms, China has been developing into a large country in costume design around the world, and the gross costume yield, export and consumption all rand ahead around the world. However, we have to face the situation that we are still not the leader in international costume industrial chains, spoken relatively we are in a stage of mid and even end range of costume industry. It is a developing trend for costume industry in the country that we have to rapidly upgrade the costume industry and changing from a costume manufacturer to a costume design brand developer. To change the adverse situation will need the hard work and persistence of generations of costume designers, in the meantime, the costume education should be exposed to internationalization, markets and modernization, and the key point for costume design education is to cultivate applied costume designers meeting what modern costume enterprise demand.

\section{CONCEPT OF APPLIED COSTUME DESIGNERS}

There are various standards for talent classification in the country, seen from the work type and object, it is divided into brain worker and manual worker; seen from purposes of production or work activities, it is divided into four kinds: academic (theoretical), engineering, technique and skillful. Seen from levels, it is divided into macroscopical, mesoscopic and microscopic. Macroscopical talents refer to high level theoretical talents, mainly in scientific research insinuations. Mesoscopic talents refer to those who own theories and technique, which are undergraduate education pursue in the country; microscopic talents refer to technicians who are engaged in highly technical work. Applied talents are required to well master basic knowledge and skills in the social production front, able to apply professional knowledge and skills in professional practices, who are not pure technical workers. The applied talents discussed in this article refer to those who own rich theoretical knowledge, the requirements may vary with posts, in a word, such talents should own professional attainments and skills, having abundant professional knowledge to instruct work, communicate with workers, sound professional ethics and quality as well as strong comprehensive capabilities, professional knowledge and various skills.

\section{A. Definition of Applied Costumer Designers}

Costume designers refer to those who own professional knowledge and diverse skills, strong design thought, professional knowledge and skills, making design more rational but not complete in technique. Most think that they are technical talents who master basic knowledge and skills of costume production front, able to engage in production. In fact, it is more than that, for example, with regard to the costume plate making, it mainly teaches students to get contents of costume plate making, roles and process flow, with the costume plate making and graded pattern theories mastered, students will be taught basic knowledge such as grade patterns, pattern making and layout and sample drawing of costume clothes and so on. Students will be taught to keep acute insight 
in digital golden ratio, able to correctly find the golden places of parting lines on clothes, as well as proportion, parting line, overlapped places on clothes and so on. First, students should know that the costume plate making can make the design more rational; second, the dialogues between designers and plate makers, the plate makers are required to complete the sample partition of designer's work as per the thought of designers in order to better show what designers want.

\section{B. Practical Significance of Applied Costume Designer Cultivation Patterns}

Applied costume designers are mesoscopic talents whose own professional knowledge and diverse skills as well as comprehensive knowledge on the basis of enterprises. Seen from the globe, the stage where technical talents and professional are in a great need and development is necessary for any country to rapidly achieve the industrialization, urbanization and modernization. Currently China is in a rapid course of industrialization, urbanization and modernization, with China's entry to the mid-term industrialization and a world-level manufacturing country, after years' opening up and development, the fashionable industry in the country is advancing in a rapid speed, becoming a large country in fashion consumption. However, the costume brand development in the country is still at the end of fashionable industry chains around the world, there are no home-made internationally famous costume brands, most of internationally famous costume brand enterprises have processing factories built in China, just because in the time of industrialization, we have qualified workers and processing factories, yet all orders are from other countries. Therefore, it is a developing trend of fashionable industry in the country that we should create famous costume brands, rapidly upgrade the costume industry and change from a processing country into a costume developer. The trend will promote a hot demand for costume designers, especially those who have stronger comprehensive capabilities. Therefore, it is necessary for cultivating applied costume designers, which will help relive the shortage of costume designers and push the leapfrog development of costume industry in the country, and it is a necessary way and selection to drive the fashionable industry development in the country.

Currently the supply of costume designers is beyond demand in domestic markets though, but many costume enterprises feel difficult to find qualified talents. Seen from it, there has been gaps between the costume design education and what modern costume enterprises, enterprises find no qualified talents, and graduates of costume design cannot find applicable posts, even they have to spend a certain period for transition after being employed. To reform the current costume design educational patterns in the country and cultivate applied costume designers can change the supply-demand contradiction in the costume design markets, promote the employment, which can bring wider employment range and stages to apply what they have learned and drive the fashionable industry development.

\section{BASIS TO CREATE APPliEd COSTUME DESIGNER CULTIVATION PATTERNS}

The costume designer cultivation patterns in colleges should be aimed at costume design markets and keep it diversified to some degree according to the school-running conditions, features and cultivation goals, in order to educate students as per characteristics of their own, and create the unique cultivation patterns suitable for the students. It should fully demonstrate students' activity, participation and respects to students' differences and exert what the students are good at compared to traditional single and modularized teaching methods, the diversified talent cultivation should be shown in talent cultivation standard, teaching management mechanisms and teaching forms. The teaching courses should have features such as diversity, dynamic, specialty and development, meeting China's demand from higher educational talents for the social development, based on the educational goals of deeply understanding and persistently promoting students' overall development, we should keep active in new exploration and ways in educational and teaching reforms and practices.

\section{A. Market Demand in Costume Designers}

Nowadays with the rapid development in IT and economy, the fashionable industry is also industrialized, in order to strengthen the competitive force, the costume industry has changed from low-cost processing to costume brand market, targeting international fashionable industry. Some costume brands, independent designer brands and fashion brands have been emerging one after another. Yet most are in a low level of design, most of the costume design in enterprises are just copied from international brands in ready-to-wear. The costume design featuring poor basis and low level is a bottleneck for the rapid development of costume design industry in the country, in order to upgrade from a processing country into a developer and make our costume design brands compete in international markets around the world, we are in a great need of local excellent costume designers who grasp domestic and international markets especially the top-end talents who are top qualified and applied brand designers. The status quo of costume industry brings a hot demand for costume designers, which bring new challenges for the costume designer cultivation. College education is required to keep up with the time to create an applied costume designer cultivation pattern in order to better meet the costume market demand, which is the need of the time and the requirements for the development of costume educational colleges.

\section{B. Design Thought Going Together with the Time}

Costume can reflect the material civilization and spiritual civilization of a society, and the people's motives for costumes and aesthetic taste will vary with the living styles and thoughts, modern costumes, as a special field in fashionable culture and consumption, carry more and more spiritual needs of the people. New cultural thoughts and culture such as mass culture, amusement culture and ergonomic and green design will have a direct influence on the costume design concept and the costume development trend. Therefore, the design thought of costume designers must be going with the time. 


\section{BASIC PRINCIPLES TO CREATE AN APPLIED COSTUME DESIGNER CULTIVATION PATTERN}

To create an applied costume designer cultivation pattern must be adapted to the development of the time, meeting the demand for talents by the time; closely follow the development trend of costume design technology to make the costume designers grasp the latest design technique and keep competent in market competition; the higher education development should change from "essence" to "mass", going toward feature, professional and individualization.

\section{A. Optimizing As a Whole}

We should take the applied costume designer cultivation pattern as a whole, aimed the optimization as a whole but not locally, and keep the overall adaptation of the applied costume designer cultivation pattern. The specialty setting shall follow the demand of the costume design markets, establish a course structure meeting college's development and students' need as per college's comprehensive evaluation and students' comprehensive quality, making to meet the teaching schedule of students' development, after graduation, all students can find jobs as wanted, meeting the needs of costume enterprises.

\section{B. Uniform Cultivation Pattern and Diverse Talent Cultivations}

In recent years, with the enrollment granted expanded in colleges and universities, the educational patterns for talent cultivation in the country has turned to most people, and more people will have an access to higher education, however, students' quality is still differing with each other. Many newly built professional colleges with costume design specialty just copy the teaching patterns and experiences of other colleges, having no features of their own, which further low the quality of students majoring in costume design. Costume designers should exert the characteristics of their own, the costume design colleges shall have clear orientations as well, aimed at design or engineering, it should be targeting. But not just copy the teaching patterns of others, if so, students can exert what they like and select where to learn with purposes, avoiding the teaching patterns copied by each other. If it is over emphasizing the uniformity, there will be unique features in the talent cultivation. If such problems fail to be well solved, the healthy development of higher education will be influenced, so we should carry out the principles of uniform cultivation pattern and diversified talents cultivation.

\section{Promote Development Through Characteristics}

The key point to create an applied costume designer cultivation pattern is to break through restrictions, creating and keeping characteristics of our own, surviving relying on characteristics and, developing with characteristics. Seen from characteristics, at present, most colleges have no obvious breakthrough in former patterns of specialty and courses. Professional colleges providing costume design should follow the costume development trend and create characteristics of their own according to the market demand.

\section{CONCLUSION}

Through over three-decade exploration and development after China's opening up and reforms, China has been developing into a large country in costume design around the world, and the gross costume yield, export and consumption all rand ahead around the world. However, we have to face the situation that we are still not the leader in international costume industrial chains, spoken relatively we are in a stage of mid and even end range of costume industry. It is a developing trend for costume industry in the country that we have to rapidly upgrade the costume industry and changing from a costume manufacturer to a costume design brand developer. To change the adverse situation will need the hard work and persistence of a great number of costume designers, in the meantime, the costume design education should be exposed to internationalization, markets and modernization, and the costume design colleges should closely follow the development of the time, adjust specialty structure in order to cultivate compound and high quality costume designers meeting what modern costume enterprises want.

\section{REFERENCES}

[1] Li Xiaoming, Clearly understand the situation and drive the job marketorientated applied costume design education - the 10th Five-Year Plan Work Outline of Applied Costume Design Specialty Committee and Work Design of the 11th Five-Year Plan [J]. Applied Costume Design Education, 2006 (5).

[2] Li Xiaoming, Chen Ping, Zhang Ming, et al, Survey Report of Needs of Applied Costume Designers [J]. Applied Costume Design Education, 2004 (8)

[3] Zha Youliang, Educational Patterns [M]. Beijing: Educational Science Publishing House, 1996.

[4] Gong Yizu, Discussion on Talents Cultivation Patterns in Colleges [M]. Jiangsu: Jiangsu Education Publishing House, 1999.

[5] Luo Ji, Cultivate Applied Talents on the Basis of Chinese Medicine Centers [J]. The Guide of Science \& Education, 2012.

[6] Li Chengwei, How can Applied Costume Designers Cultivation Break through Confusions and Become Mature [J]. Applied Costume Design Education, 2006 (5). 